\title{
Use of Serology and Thin-Layer Chromatography for the Assembly of an Authenticated Collection of Serovars Within the Mycobacterium avium-Mycobacterium intracellulare- Mycobacterium scrofulaceum Complex
}

\author{
ANNA Y. TSANG, ${ }^{1}$ ILGA DRUPA, ${ }^{1}$ MIRTA GOLDBERG, ${ }^{1} \mathrm{~J}$. KENNETH MCCLATCHY, ${ }^{1}$ AND \\ PATRICK J. BRENNAN ${ }^{2 *}$ \\ Department of Clinical Laboratories, National Jewish Hospital and Research Center, Denver, Colorado \\ 80206, ${ }^{1}$ and Department of Microbiology, Colorado State University, Fort Collins, Colorado $80523^{2}$
}

The seroagglutination test devised by Schaefer (Methods Microbiol. 13:323344,1980 ) and the thin-layer chromatography procedure of Brennan et al. (J. Clin. Microbiol. 8:374-379, 1978; 15:447-455, 1982) were used to assemble an authenticated collection composed of 30 of the 31 known serovars of the Mycobacterium avium-Mycobacterium intracellulare-Mycobacterium scrofulaceum complex, and from these serovars a new set of absorbed specific homologous rabbit antisera was prepared. Isolates of a few serovars (serovars 18, 41, and 43) showed the expected seroagglutination reactions but also produced several thin-layer chromatographic profiles, a phenomenon which places further emphasis on the need to use both thin-layer chromatography and serological analyses when the epidemiological aspects of nontuberculous mycobacteria are examined.

The recovery of nontuberculous mycobacteria (the so-called atypical mycobacteria) from patient specimens and from the environment is of concern to microbioiogists, epidemiologists, and physicians (16). Although standard biochemical methods of identification (23) are used in many clinical microbiology laboratories, the most discriminating and sensitive epidemiological test is the seroagglutination assay devised by Schaefer (18-21). This assay was primarily responsible for the recognition of 31 serovars (serotypes) within Mycobacterium avium (serovars 1 through 3), Mycobacterium intracellulare (serovars 4 through 28), and Mycobacterium scrofulaceum (serovars 41 through 43) (this assemblage is known as the $M$. avium- $M$. intracellulare-M. scrofulaceum serocomplex). Despite the wide acceptance and use of seroagglutination, no fully authenticated collection of $M$. avium- $M$. intracellulare- $M$. scrofulaceum complex serovars and homologous antisera exists, and this has seriously hampered epidemiological studies. In this paper we describe our efforts to prepare a collection of reference strains.

The seroagglutination test can be used only with smooth-colony-forming mycobacteria due to the presence of type-specific antigens on the cell surfaces of these organisms; rough colony variants lack these surface antigens and agglutinate spontaneously with all antisera (21). Recently, we defined the structures of these anti- gens $(1,3-5,7)$ and from this information developed thin-layer chromatography (TLC) procedures for the identification of members of the $M$. avium- $M$. intracellulare $-M$. scrofulaceum complex $(6,8)$. These procedures have now been combined with seroagglutination to help choose prototype strains of the $M$. avium$M$. intracellulare-M. scrofulaceum complex.

\section{MATERIALS AND METHODS}

Sources of strains. Many of the strains used in this study were from the original collection inherited from the late W. B. Schaefer (20). Others were obtained from other investigators or were collected from patients referred to National Jewish Hospital.

Growth of strains. The organisms were cultured in 5$\mathrm{ml}$ portions of $7 \mathrm{H} 11$ broth (9). They were incubated at $37^{\circ} \mathrm{C}$ for 1 week or until McFarland no. 1 turbidity developed. Routinely, a loopful of a culture was streaked onto blood agar and 7H11 agar plates to ensure the absence of contamination and the presence of one colony type. A $0.3-\mathrm{ml}$ inoculum was then spread in $0.1-\mathrm{ml}$ amounts over the surfaces of three petri dishes containing 7H11 agar and incubated at $37^{\circ} \mathrm{C}$ until luxuriant growth was obtained. The bacteria were harvested by adding 5 to $10 \mathrm{ml}$ of $0.5 \%$ phenol in phosphate-buffered saline (PPBS) to a plate, scraping colonies off with a bent capillary pipette, and allowing the resulting suspension to stand for $5 \mathrm{~min}$ before transferring it to a screw-capped tube $(20$ by $150 \mathrm{~mm})$. The bacterial suspension was maintained in this state at room temperature for a few days to facilitate the formation of a homogeneous suspension. 
Seroagglutination. Each bacterial suspension was adjusted with PPBS to an optical density at $525 \mathrm{~nm}$ of 0.3 with a Coleman Junior spectrophotometer. This suspension was used both in the seroagglutination assay and to elicit antibody production in rabbits.

The seroagglutination procedure used was basically that developed by Schaefer (18), with some key modifications. To culture tubes $(12$ by $75 \mathrm{~mm}), 0.5-\mathrm{ml}$ portions of the working dilution of each antiserum were added, followed by $0.5-\mathrm{ml}$ portions of the bacterial suspension. Control tubes containing $0.5 \mathrm{ml}$ of PPBS and $0.5 \mathrm{ml}$ of bacterial suspension were also included. The tubes were shaken and placed in an incubator at $37^{\circ} \mathrm{C}$, and after 3 and $24 \mathrm{~h}$ they were removed to analyze the extent of agglutination. Agglutination was graded from no agglutination to complete agglutination on a scale of 0 to $4+$. A strain was given a score of $4+$ if the suspension agglutinated completely with a pair of antisera from a particular serovar. In most instances type-specific agglutination occurred within $3 \mathrm{~h}$; however, sometimes the reaction took $24 \mathrm{~h}$ to develop. When agglutination occurred with many different antisera as well as in the control tubes, spontaneous agglutination was recorded. When one tube of a pair agglutinated to give less than a $4+$ response and no agglutination with other sera was evident, a tentative identification was made; final identification awaited the results of TLC. When there was agglutination in one tube of a pair or no agglutination occurred, untypable was recorded.

TLC. A minimum of $5 \mathrm{mg}$ of bacilli grown as described above was extracted with chloroform-methanol as described previously (8). The resulting clear extracts were then treated with $0.2 \mathrm{M} \mathrm{NaOH}$ (8), which had the dual effect of destroying nonspecific glycerides and simplifying the visualization of characteristic C-mycoside glycopeptidolipid antigens (1). The alkali-stable lipids were then applied to layers of silica gel (Redi Plate; Analtech, Inc.) and chromatographed in either chloroform-methanol-water $(65: 25: 4$; solvent II of Brennan et al. [8]) or chloroform-methanol-water ('60:16:2; solvent III of Brennan et al. [8]). Air-dried plates were sprayed with orcinol- $\mathrm{H}_{2} \mathrm{SO}_{4}$ as described previously (8). The type-specific glycolipid antigens responded to the orcinol spray with a characteristic yellowish gold color due to the inherent 6-deoxyhexoses.

Preparation of reference antisera. A bacterial suspension $(1.0 \mathrm{ml})$ in PPBS, which was prepared as described above, was injected into the ear veins of 3month-old New Zealand white rabbits twice each week for 2 weeks, and sera was titrated as described by Schaefer (18).

\section{RESULTS}

Evaluation of reference strains. Over the past 6 to 7 years we collected many strains which were designated members of the $M$. avium-M. intracellulare- $M$. scrofulaceum complex and were regarded as suitable reference strains for the identification and classification of atypical mycobacteria. We doubted the validity of several of these strains and thus set out to authenticate all of them by both seroagglutination and TLC to arrive at a reference serotyping collection, which could complement the Trudeau Mycobacterial Collection already housed at the National Jewish Hospital and Research Center (17).

Table 1 shows the results of our seroagglutination evaluation of 61 of the assembled strains, in which two antisera were used for each serovar. The results were equivocal for 23 of the 61 isolates (strains B-87, 6194, 14141-1395, 16741Cardiff, P55, TMC 1463, 4443-1237, 34540Wales, 23435, SJB 2, 6450-204, TMC 1461, 72482, Dent-Dent, Simpson, TMC 1473, ATCC 15987, Darden, 10409, 5154 O'Connor, Cox A44, McKenzie, and Lane 3081). The lipids from all 61 strains were treated with alkali and chromatographed on thin-layer plates, and their patterns were compared with one another and with the patterns published previously (6-8). Figures $1 \mathrm{~A}$ and $\mathrm{B}$ demonstrate the approach used with many of the strains. TLC removed any doubt regarding the identities of strains TMC 1463 , 4443-1237, 23435, SJB 2, Dent-Dent, Simpson, and Lane 3081. A comparison of strain 6450-204 with strain 17584-286 (the prototype strain in that it displayed perfect agglutination and the pattern was consistent with that of another strain of serovar 9 [5]) showed that strain 6450204 was indeed a serovar 9 strain. Likewise, TLC of strain 34540-Wales and other strains previously identified as serovar 6 showed that the pattern in Fig. 1A (Fig. 1A, lane 6) was entirely characteristic of serovar 6. Also, it appeared from TLC that strain B87 is a serovar 1 strain.

TLC also provided a sound basis for the rejection of isolates which gave equivocal serological results. For example, the three strains originally identified as serovar 2 presented a special problem in that serology alone did not provide sure confirmation for any one of them. On the basis of TLC, strain 6194 (Fig. 1A, lane 2a) was not even a member of the $M$. avium- $M$. intracellulare-M. scrofulaceum complex. Likewise, strain 16741-Cardiff (Fig. 1A, lane 2c) which originally was regarded as a serovar 2 strain but spontaneously agglutinated with antisera, was not a serovar 2 strain according to the TLC pattern (this was more evident when the less polar solvent, solvent III, was used). Hence, strain 14141 is the prototype serovar 2 strain. This is the original Schaefer serotype 2 strain (21), and although not entirely satisfactory in that it cross-reacts with serovars $1,6,8$, and 18 , it is the only available serovar 2 strain with harmonious serological and TLC results.

With the majority of strains, agglutination and TLC were highly complementary; this is obvious from a comparison of the serological results in Table 1 and the TLC profiles in Fig. 1. However, there were exceptions, such as the 
two strains of serovar 22, strains 10409 and 5154 O'Connor (Fig. 1B, lanes 22a and 22b). TLC showed that the faster-moving spots in strain 5154 O'Connor were diminished compared with strain 10409. Thus, it appears that the immunological determinants were associated with the slower component present in both strains. In some instances serology was clearly superior to TLC; serovars 10 and 11 (once known as serovars III and IIIa) were indistinguishable by TLC but could be differentiated by using cross-absorbed antisera. Clearly, in an exercise of this kind both serology and TLC are necessary. For example, it is very difficult to distinguish among serovars $1,4,6$, and 20 by TLC alone (Fig. 1A and B) (3). The results of TLC for all 61 isolates are summarized in Table 1.

The two strains of serovar 18, strains 2219 and Melnick (Fig. 1B, lanes 18a and b), are good examples of an aberrance which we observed on occasion. Although the agglutination results for these two strains were unequivocal (Table 1), two distinct TLC patterns were observed. This phenomenon was further explored by comparing strains 2219 and Melnick with an isolate from a clinical source (strain O'Connor-4990). Strain O'Connor-4990 produced a pattern identical to that of strain 2219 (data not shown). Thus, apparently there are two distinct patterns for serovar 18. There is evidence which suggests that at least some isolates of serovar 18 exhibit serological and biochemical features that more nearly resemble Mycobacterium simiae II than $M$. intracellulare (2). Indeed, we have shown that both $M$. simiae I and $M$. simiae II contain C-mycoside glycopeptidolipids similar to those in M. intracellulare (P. J. Brennan and V. Barr, unpublished data). However, we have not yet determined which, if any, of the two serovar 18 strains correspond to $M$. simiae serovar 1 .

The serovar 41 and 43 strains also produced multiple TLC patterns (Table 2 and Fig. 2). The three isolates of serovar $\mathbf{4 1}$ produced identical, perfect agglutination results (Table 2), yet TLC showed that only two strains (strains Bridge and 2729 Cardiff) had identical TLC profiles (Fig. 2). When these two strains were compared with three other strains (Fig. 2A, lanes 4 through 6) which had been identified as serovar 41 strains by agglutination, we found that there were in fact three TLC patterns for serovar 41 isolates (the pattern shown in Fig. 2A, lanes 1 and 5 ; the pattern shown in Fig. 2A, lanes 2 and 3; and the pattern shown in Fig. 2A, lanes 4 and 6). Isolates of serovar 43 showed a similar trend. Of the three strains identified as members of serovar 43 in Table 2, only two (strains Brooks and GauseAnderson) (Fig. 2C, lanes 1 and 3) produced identical patterns. Strain M-150 produced a different pattern, which corresponded to that of a fourth isolate (Fig. 2C, lane 4). On the other hand, all isolates which were identified as serovar 42 strains produced identical TLC profiles (Fig. 2) (there were insignificant differences among the minor lipids).

Preparation of antisera to authenticated strains. We prepared a new set of rabbit antisera to the strains which were satisfactorily serotyped by both agglutination and TLC. A $5-\mathrm{ml}$ serum sample was titrated by using both the immunizing strain and suspensions of other strains of the same serovar and other serovars. A titer of 1:160 or greater against the homologous strain was considered acceptable, and the rabbit was bled. Rabbits showing a titer of less than 1:160 were given one or two more injections of the bacterial suspension. Rabbits were sacrificed at the end of 5 weeks if no improvement in titer was evident. The extent of crossreactivity that occurred among serovars and antisera has been described previously (21). With the new antisera, in most instances in which cross-reactivity occurred, the cross-reacting strains were used to absorb out cross-reacting antibodies, so that cross-reactivity occurred at a titer of less than 1:80. We are now using these sera, in addition to the older sera, for purposes of identification and classification of atypical mycobacterial isolates, and they are available to bona fide investigators for reference purposes. We shall describe elsewhere the extent of cross-reactivity among the sera, as determined by both agglutination and an enzymelinked immunosorbent assay.

\section{DISCUSSION}

Interest in the $M$. avium-M. intracellulare- $M$. scrofulaceum complex stems from the fact that these organisms are the most common atypical mycobacteria and the fact that the members of this group isolated from human sources are, for the most part, refractory to chemotherapy (10, 24). Taxonomically, $M$. scrofulaceum may be distinguished from $M$. avium and $M$. intracellulare by biochemical and morphological characteristics (23). M. scrofulaceum strains are scotochromogenic and, in contrast to $M$. intracellulare, urease positive. Moreover, the antigenic structures of these species differ $(4,5$, 7), thereby allowing differentiation by both seroagglutination and TLC. Schaefer (18) and Marks et al. (13) described three different serovars of $M$. avium (serovars 1 through 3 ), and Wolinsky and Schaefer (25) isolated from human patients and domestic animals strains which were serologically distinct from the serovars of $M$. avium but had identical biochemical properties. In general, the $M$. intracellulare serovars are totally avirulent to chickens; exceptions are 
TABLE 1. Results of seroagglutination and TLC for $61 M$. avium-M. intracellulare-M. scrofulaceum complex strains

\begin{tabular}{|c|c|c|c|c|c|}
\hline \multirow{2}{*}{$\begin{array}{c}\text { Original } \\
\text { serovar } \\
\text { designation }\end{array}$} & \multirow[t]{2}{*}{ Strain } & \multicolumn{2}{|c|}{$\begin{array}{l}\text { Agglutination reactions } \\
\text { with homologous antisera }\end{array}$} & \multicolumn{2}{|c|}{ Serovar based on: } \\
\hline & & Serum 1 & Serum 2 & Seroagglutination & TLC $^{a}$ \\
\hline \multirow[t]{5}{*}{1} & B-87 & $\mathrm{SA}^{b}$ & SA & $\mathrm{ND}^{c}$ & 1 \\
\hline & B-92 & $4+$ & $2+$ & 1 & 1 \\
\hline & $11907-300$ & $4+$ & $4+$ & 1 & 1 \\
\hline & $16909-2380$ & $4+$ & $4+$ & 1 & 1 \\
\hline & McKenna & $4+$ & $3+$ & 1 & 1 \\
\hline \multirow[t]{3}{*}{2} & 6194 & 0 & 0 & Untypable & $\mathrm{NM}^{d}$ \\
\hline & $14141-1395$ & $3+$ & $4+$ & 2 & 2 \\
\hline & 16741-Cardiff & SA & SA & ND & $\mathrm{NT} 2^{e}$ \\
\hline \multirow[t]{2}{*}{3} & 6195 & $4+$ & $4+$ & 3 & 3 \\
\hline & 128-Germany & $4+$ & $4+$ & 3 & 3 \\
\hline \multirow[t]{4}{*}{4} & $13528-1079$ & $4+$ & $4+$ & 4 & 4 \\
\hline & P-55 & $4+$ & 0 & 4 & 4 \\
\hline & TMC 1463 & $4+$ & 0 & 4 & 4 \\
\hline & 4992 Montenes & $4+$ & $4+$ & 4 & 4 \\
\hline \multirow[t]{2}{*}{5} & $25546-759$ & $4+$ & $4+$ & 5 & 5 \\
\hline & $4443-1237$ & $4+$ & 0 & 5 & 5 \\
\hline 6 & 34540-Wales & $4+$ & 0 & 6 & 6 \\
\hline \multirow{2}{*}{7} & P-49 & $4+$ & $4+$ & 7 & 7 \\
\hline & 157-Manten & $4+$ & $4+$ & 7 & 7 \\
\hline \multirow[t]{2}{*}{8} & 23435 & $4+$ & 0 & 8 & 8 \\
\hline & SJB 2 & $4+$ & 0 & 8 & 8 \\
\hline \multirow[t]{2}{*}{9} & $6450-204$ & $3+$ & 0 & 9 & 9 \\
\hline & $17584-286$ & $4+$ & $4+$ & 9 & 9 \\
\hline \multirow{2}{*}{10} & $1602-1965$ & $4+$ & $3+$ & 10 & 10 \\
\hline & TMC-1461 & 0 & $3+$ & ND & 10 or 11 \\
\hline \multirow[t]{2}{*}{11} & $14186-1424$ & $4+$ & $4+$ & 11 & 11 \\
\hline & TMC-1462 & $3+$ & $4+$ & ND & 11 \\
\hline \multirow[t]{2}{*}{12} & P-42 & $4+$ & $4+$ & 12 & 12 \\
\hline & Woodduck & $4+$ & $4+$ & 12 & 12 \\
\hline \multirow[t]{3}{*}{13} & $72-482$ & 0 & \pm & ND & 13 \\
\hline & ATCC 25122 & $4+$ & $\overrightarrow{4}+$ & 13 & 13 \\
\hline & TMC 1466 & $4+$ & $4+$ & 13 & 13 \\
\hline \multirow[t]{2}{*}{14} & P-39 & $4+$ & $4+$ & 14 & 14 \\
\hline & Edgar Boone & $3+$ & $4+$ & 14 & 14 \\
\hline 15 & Dent-Dent ${ }^{f}$ & $4+$ & 0 & 15 & 15 \\
\hline
\end{tabular}

strains of serovars 4 through 9 , which do show marked degrees of virulence. These have been designated the intermediate group (21). Thus, the case for differentiating members of the $M$. avium- $M$. intracellulare-M. scrofulaceum complex only on biochemical or virulence grounds is not strong, and separation must depend on serological analyses. The recent findings of Brennan et al. $(4,5,7)$ which showed that the typing antigens of members of the $M$. avium-M. intracellulare-M. scrofulaceum complex are all distinct but which were based on the presence of a communal C-mycoside confirm the relationship between serovars and justify categorization of these organisms into a complex.

Throughout his investigations, Schaefer used seroagglutination to arrive at precise identifications, classifications, and epidemiological trends for members of the $M$. avium-M. intracellulare$M$. scrofulaceum complex. On the other hand,
Marks and colleagues $(11-15,22)$ were able to accomplish similar ends by identifying serotypes solely on the basis of a set of characteristic lipids. Later, Brennan et al. $(4,5,7)$ characterized these lipids and showed that they were in fact the antigens involved in the serological tests. Moreover, these workers $(3,6)$ further modified and simplified the TLC procedures of Marks et al. to make them more amenable to routine diagnostic work.

In the current work, we used adaptations of the serotyping and TLC procedures to formulate an authenticated collection of $M$. avium-M. intracellulare $-M$. scrofulaceum complex strains and from these strains prepared corresponding antisera. This collection contains at least one strain of serovars 1 through 27 and 41 through 43. We have not yet collected enough isolates of serovar 28 to reevaluate (6) the TLC profile of this group. In the current work, we also pre- 
TABLE 1-Continued

\begin{tabular}{|c|c|c|c|c|c|}
\hline \multirow{2}{*}{$\begin{array}{l}\text { Original } \\
\text { serovar } \\
\text { designation }\end{array}$} & \multirow{2}{*}{ Strain } & \multicolumn{2}{|c|}{$\begin{array}{l}\text { Agglutination reactions } \\
\text { with homologous antisera }\end{array}$} & \multicolumn{2}{|c|}{ Serovar based on: } \\
\hline & & Serum 1 & Serum 2 & Seroagglutination & TLC $^{a}$ \\
\hline \multirow{4}{*}{16} & Simpson & $4+$ & $2+$ & 15 & 15 \\
\hline & TMC 1473 & $3+$ & 0 & 15 & 15 \\
\hline & Yandle-Yandle & $3+$ & $4+$ & 16 & 16 \\
\hline & ATCC 15987 & \pm & $4+$ & 16 & 16 \\
\hline 17 & P-54 & $4+$ & $4+$ & 17 & 17 \\
\hline \multirow{2}{*}{18} & 2219 & $4+$ & $4+$ & 18 & 18 \\
\hline & Melnick & $4+$ & $4+$ & 18 & 18 \\
\hline \multirow[t]{3}{*}{19} & W-552 & $4+$ & $4+$ & 19 & 19 \\
\hline & Darden & 0 & $4+$ & ND & 19 \\
\hline & Sorell & $4+$ & $4+$ & 19 & 19 \\
\hline \multirow[t]{3}{*}{20} & $72-1352$ & $3+$ & $4+$ & 20 & 20 \\
\hline & AT-545 Findley & $4+$ & $4+$ & 20 & 20 \\
\hline & TMC-1419 & $4+$ & $4+$ & 20 & 20 \\
\hline \multirow[t]{2}{*}{21} & 2993 & $4+$ & $4+$ & 21 & 21 \\
\hline & T-77 & $4+$ & $4+$ & 21 & 21 \\
\hline \multirow[t]{2}{*}{22} & 10409 & 0 & $4+$ & 22 & 22 \\
\hline & 5154 O'Connor & $2+$ & $4+$ & 22 & 22 \\
\hline \multirow[t]{2}{*}{23} & 23393 & $4+$ & $4+$ & 23 & 23 \\
\hline & CDC 1214 & $4+$ & $4+$ & 23 & 23 \\
\hline 24 & 12645 & $4+$ & $4+$ & 24 & 24 \\
\hline \multirow[t]{2}{*}{25} & $72-888$ & $4+$ & $4+$ & 25 & 25 \\
\hline & CDC 1195 & $4+$ & $4+$ & 25 & 25 \\
\hline \multirow[t]{3}{*}{26} & Cox A-44 & $1+$ & $2+$ & 26 & 26 \\
\hline & McKenzie & 0 & $3+$ & 26 & 26 \\
\hline & 1244 Hillberry & $3+$ & $4+$ & 26 & 26 \\
\hline 27 & Lane 3081 & 0 & $4+$ & 27 & 27 \\
\hline
\end{tabular}

${ }^{a}$ See Fig. 1 for some of the TLC patterns.

${ }^{b}$ SA, Spontaneous agglutination.

$c$ ND, No decision.

${ }^{d} \mathrm{NM}$, Not a member of the $M$. avium-M. intracellulare-M. scrofulaceum complex.

- NT2, Not serovar 2.

$f$ In the past, serovars were given proper names (usually names of patients) rather than identified by numbers (24). For example, serovar 15 was named Dent. The second Dent is the strain designation. Therefore, Dent-Dent could also be called serovar 15 , strain Dent.

pared the lipids of each of the serovars and have described the characteristic lipid profiles. It should be realized that the photographs in previous papers $(6,8)$ were generally of single isolates of individual serovars and should now be interpreted in light of evidence that serovars 18,41 , and 43 gave several TLC patterns. Jenkins (11) described this same phenomenon to some extent. In his study, 15 of 19 strains identified as serovar 42 strains had similar TLC patterns, whereas 4 did not conform. For 14 strains of serovar 41 there was little agreement. The lack of consistent reproducible sets of glycopeptidolipid antigens in strains of some serovars is puzzling and has not been explained. It should be noted in Fig. 2 that despite divergent overall patterns, some lipids are shared, and these may be the immunodominant varieties. It is also possible that the glycolipid antigens of these serovars are chemically unstable and are degrad- ed to smaller fragments, a possibility that is consistent with the simpler patterns reported previously $(6,7)$. Perhaps all strains of one serovar contain a shared immunodominant oligosaccharide segment on different "cores" (4, 7).

There is little doubt that in nature there are considerably more $M$. avium- $M$. intracellulare$M$. scrofulaceum complex serovars than the 31 currently recognized. Combined serology and TLC is particularly useful for probing the extent of the $M$. avium- $M$. intracellulare- $M$. scrofulaceum complex. In our work, isolates which show spontaneous agglutination or no agglutination are routinely subjected to TLC analysis, and the resulting patterns are then compared with those of members of our authenticated collection. Over the past 2 years we have subjected hundreds of isolates to this regimen, and we are convinced that there are at least $\mathbf{4 0}$ 


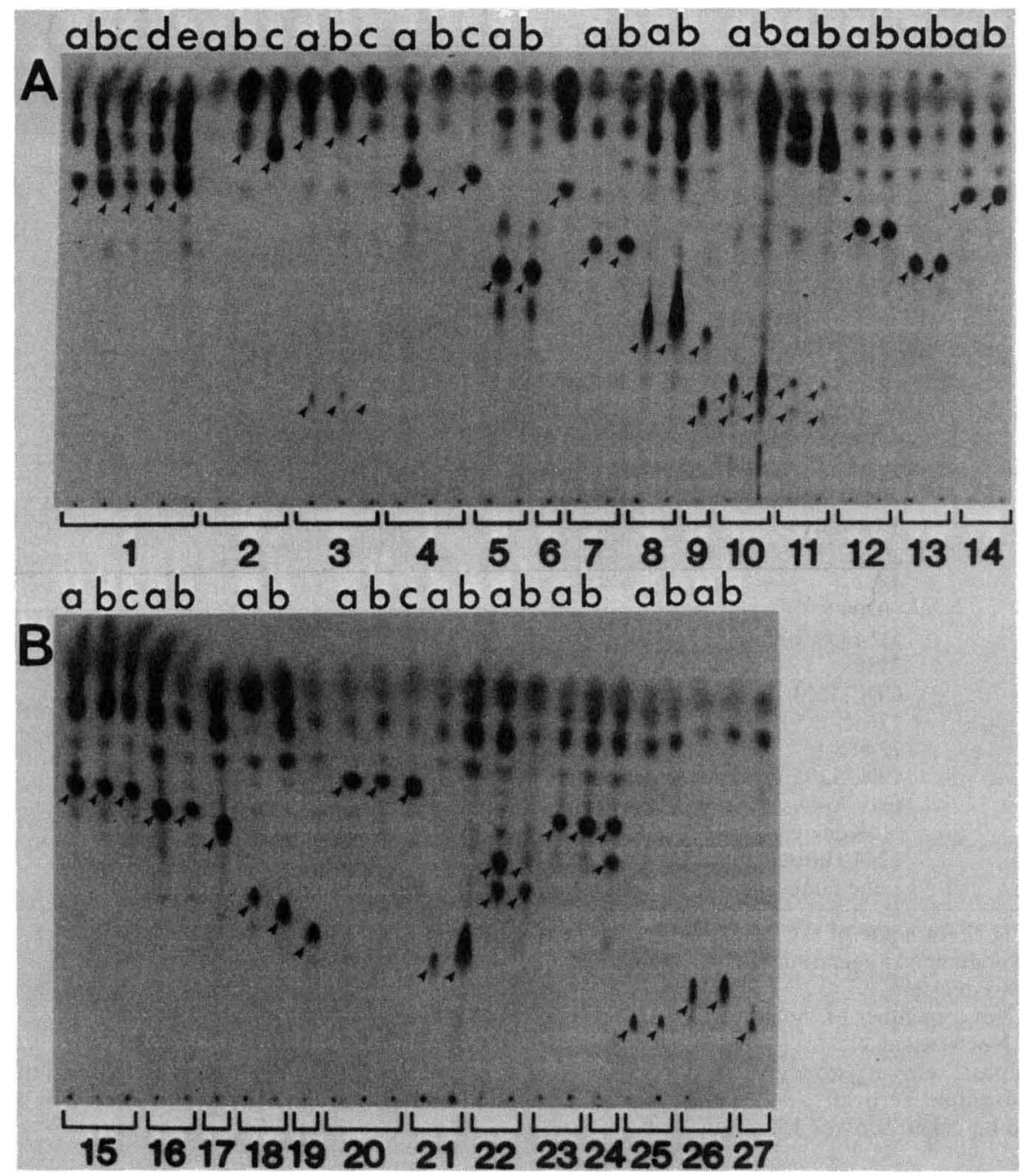

FIG. 1. TLC in $\mathrm{CHCl}_{3}-\mathrm{CH}_{3} \mathrm{OH}$-water (65:25:4; solvent II) of the lipids from some of the strains listed in Table 1. Lipids were extracted from dried cultures with $\mathrm{CHCl}_{3}-\mathrm{CH}_{3} \mathrm{OH}(2: 1)$ and treated with alkali to simplify the pattern of glycopeptidolipids (8). Plates were sprayed with orcinol- $\mathrm{H}_{2} \mathrm{SO}_{4}$ to give a characteristic gold color. (A) Serovars 1 through 14. Lanes 1a through e, serovar 1 (lane 1a, strain B-87; lane 1b, strain B-92; lane 1c, strain 11907-300; lane 1d, strain 16909-2380; lane 1e, strain McKenna); lanes 2a through c, serovar 2 (lane 2a, strain 6194; lane 2b, strain 14141-1395; lane 2c, strain 16741-Cardiff); lanes 3a through c, serovar 3 (lane 3a, strain 6195; lane 3b, strain 6197; lane 3c, strain 128-Germany); lanes 4a through c, serovar 4 (lane 4a, strain 13528-1079; lane 4b, strain P-55; lane 4c, strain TMC 1463); lanes 5a and b, serovar 5 (lane 5a, strain 25546-759; lane 5b, strain 4443-1237); lane 6, serovar 6 (strain 34540-Wales); lanes 7a and b, serovar 7 (lane 7a, strain P-49; lane 7b, strain 157-Manten); lanes 8a and b, serovar 8 (lane 8a, strain 23435; lane 8b, strain SJB 2); lane 9, serovar 9 (strain 6450204); lanes 10a and b, serovar 10 (lane 10a, strain 1602-1965; lane 10b, strain TMC 1461); lanes 11a and b, serovar 11 (lane 11a, strain 14186-1424; lane 11b, strain TMC 1462); lanes 12a and b, serovar 12 (lane 12a, strain P-42; lane 12b, strain Wooduck); lanes 13a and b, serovar 13 (lane 13a, strain 72-482; lane 13b, strain ATCC 25122); lanes 14a and b, serovar 14 (lane 14a, strain P-39; lane 14b, strain Edgar-Boone). (B) Serovars 15 through 27. Lanes 15a through c, serovar 15 (lane 15a, strain Dent-Dent; lane 15b, strain Simpson; lane 15c, strain TMC 1473); lanes 16a and b, serovar 16 (lane 16a, strain Yandle-Yandle; lane 16b, strain ATCC 15987); lane 17, serovar 17 (strain P-54); lanes 18a and b, serovar 18 (lane 18a, strain 2219; lane 18b, strain Melnick); lane 19, serovar 19 (strain W-552); lanes 20a through c, serovar 20 (lane 20a, strain 72-1352; lane 20b, strain AT-545 Findley; lane 20c, strain TMC 1419); lanes 21a and b, serovar 21 (lane 21a, strain 2993; lane 21b strain T-77); lanes 22a and b, serovar 22 (lane 22a, strain 10409; lane 22b, strain 5154 O'Connor); lanes 23a and b, serovar 23 (lane 23a, strain 23393; lane 23b, strain CDC-1214); lane 24, serovar 24 (strain 12645); lanes 25a and b, serovar 25 (lane 25a, strain 72-888; lane 25b, strain CDC-1195); lanes 26a and b, serovar 26 (lane 26a, strain MacKenzie; lane 26b, strain Cox A-44); lane 27, serovar 27 (strain 3081). The arrowheads indicate the major characteristic lipid antigen(s) of each serovar. 
TABLE 2. Results of seroagglutination for strains on serovars 41 through 43

\begin{tabular}{|c|c|c|c|c|}
\hline \multirow{2}{*}{$\begin{array}{c}\text { Original } \\
\text { serovar } \\
\text { designation }\end{array}$} & \multirow[t]{2}{*}{ Strain } & \multicolumn{2}{|c|}{$\begin{array}{l}\text { Agglutination } \\
\text { reactions with } \\
\text { homologous } \\
\text { antisera }\end{array}$} & \multirow{2}{*}{$\begin{array}{c}\begin{array}{c}\text { Serovar } \\
\text { based on } \\
\text { seroaggluti- } \\
\text { nation }^{a}\end{array} \\
\end{array}$} \\
\hline & & $\begin{array}{c}\text { Serum } \\
1\end{array}$ & $\underset{2}{\text { Serum }}$ & \\
\hline 41 & $\left\{\begin{array}{l}968 \\
\text { Bridge } \\
2729 \text { Cardiff }\end{array}\right.$ & $\begin{array}{l}4+ \\
4+ \\
4+\end{array}$ & $\begin{array}{l}4+ \\
4+ \\
4+\end{array}$ & $\begin{array}{l}41 \\
41 \\
41\end{array}$ \\
\hline 42 & $\begin{array}{l}\text { EW } 10407 \\
\text { CDC } 1198 \\
\text { Lunning } 1 \\
\text { Lunning } 2\end{array}$ & $\begin{array}{l}4+ \\
4+ \\
4+ \\
4+\end{array}$ & $\begin{array}{l}4+ \\
4+ \\
4+ \\
4+\end{array}$ & $\begin{array}{l}42 \\
42 \\
42 \\
42\end{array}$ \\
\hline 43 & $\begin{array}{l}\text { Brooks } \\
\text { M-150 } \\
\text { Gause-Andersen }\end{array}$ & $\begin{array}{l}4+ \\
4+ \\
3+\end{array}$ & $\begin{array}{l}4+ \\
4+ \\
4+\end{array}$ & $\begin{array}{l}43 \\
43 \\
43\end{array}$ \\
\hline
\end{tabular}

${ }^{a}$ See Fig. 2 for TLC results.

members of the $M$. avium- $M$. intracellulare- $M$. scrofulaceum complex.

Yet another challenge concerns the authentication of atypical mycobacterial species other

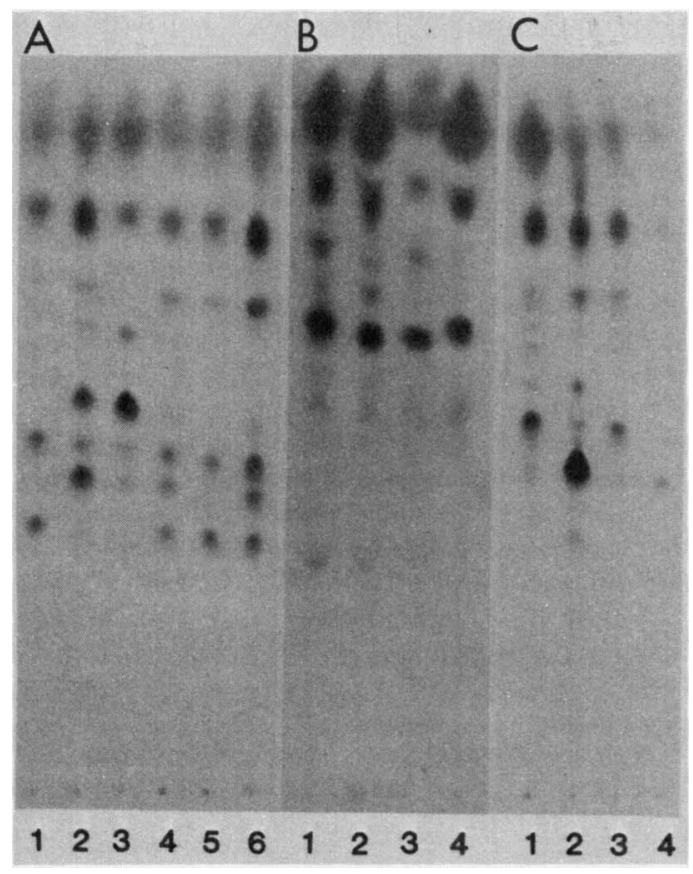

FIG. 2. TLC in solvent II of the lipids from strains of serovars 41 through 43. (A) Serovar 41. Lane 1, strain 968; lane 2, strain Bridge; lane 3, strain 2729 Cardiff; lane 4, strain Tsuk 1; lane 5, strain Tsuk 2; lane 6, strain Tsuk 3. (B) Serovar 42. Lane 1, strain EW 10407; lane 2, strain CDC-1198; lane 3, strain Lunning 1; lane 4, strain Lunning 2. (C) Serovar 43. Lane 1, strain Brooks; lane 2, strain M-150; lane 3, strain Gause-Anderson; lane 4, strain Gause-1. than members of the $M$. avium- $M$. intracellulare-M. scrofulaceum complex. Marks and colleagues $(11,12,14,15,22)$ and we (6) have determined that many of these species contain a characteristic array of glycolipids and that these glycolipids are the basis of the serological typing procedure. Recently, we have established that these lipids belong to two classes, alkali-stable lipids related to the C-mycoside glycopeptidolipids and alkali-labile lipids, which are basically acylated oligosaccharides (P. J. Brennan and S. W. Hunter, (Fed. Proc. 41:1173, 1982). The elucidation of the latter structures should help rationalize procedures for the identification and classification of the nontuberculous mycobacteria which are not members of the $M$. avium-M. intracellulare-M. scrofulaceum complex.

\section{ACKNOWLEDGMENTS}

This work was supported by Public Health Service contract AI-02641 and Public Health Service grant AI-18357 from the United States-Japan Medical Sciences Program, National Institutes of Allergy and Infectious Diseases.

We acknowledge and thank the many investigators (too numerous to mention individually) who supplied us with invaluable cultures.

\section{LITERATURE CITED}

Barrow, W. W., B. P. Ullom, and P. J. Brennan. 1980. Peptidoglycolipid nature of the superficial cell wall sheath of smooth-colony-forming mycobacteria. J. Bacteriol. 144:814-822.

Boisvert, H., and C. Truffot. 1979. Relations entre Mycobacterium simiae et le complexe $M$. avium-intracellularescrofulaceum. Ann. Microbiol. (Paris) 130B:457-466.

Brennan, P. J. 1981. Structures of the typing antigens of atypical mycobacteria. A brief review of present knowledge. Rev. Infect. Dis. 3:905-913.

Brennan, P. J., G. O. Aspinall, and J. E. Nam Shin. 1981. Structure of the specific oligosaccharides from the glycopeptidolipid antigens of serovars in the Mycobacterium avium-Mycobacterium intracellulare-Mycobacterium scrofulaceum complex. J. Biol. Chem. 256:6817-6822.

Brennan, P. J., and M. B. Goren. 1979. Structural studies on the type-specific antigens and lipids of the Mycobacterium avium-Mycobacterium intracellulare-Mycobacterium scrofulaceum serocomplex. J. Biol. Chem. 254:42054211.

Brennan, P. J., M. Heifets, and B. P. Ullom. 1982. Thinlayer chromatography of lipid antigens as a means of identifying nontuberculous mycobacteria. J. Clin. Microbiol. 15:447-455.

Brennan, P. J., H. Mayer, G. O. Aspinall, and J. E. Nam Shin. 1980. Structures of the glycopeptidolipid antigens from serovars in the Mycobacterium avium-Mycobacterium intracellulare-Mycobacterium scrofulaceum serocomplex. Eur. J. Biochem. 115:7-15.

Brennan, P. J., M. Souhrada, B. Ullom, J. K. MeClatchy, and M. B. Goren. 1978. Identification of atypical mycobacteria by thin-layer chromatography of their surface antigens. J. Clin. Microbiol. 8:374-379.

9. Cohn, M. L., R. F. Waggoner, and J. K. MeClatchy. 1968. The 7H11 media for the cultivation of mycobacteria. Am. Rev. Respir. Dis. 98:295-296.

10. Davidson, P. T. 1979. The management of disease with atypical mycobacteria. Clin. Notes Respir. Dis. 18:3-13.

11. Jenkins, P. A. 1981. Lipid analysis in the identification of mycobacteria —an appraisal. Rev. Infect. Dis. 3:862-866. 
12. Jenkins, P. A., J. Marks, and W. B. Schaefer. 1972. Thinlayer chromatography of mycobacterial lipids as an aid to classification: the scotochromogenic mycobacteria, including Mycobacterium scrofulaceum, $M$. xenopi, $M$. aquae, $M$. gordonae, $M$. flavescens. Tubercle 53:118127.

13. Marks, J., P. A. Jenkins, and W. B. Schaefer. 1969. Identification and incidence of a third type of Mycobacterium avium. Tubercle 50:394-395.

14. Marks, J., P. A. Jenkins, and M. Tsukamura. 1972. Mycobacterium szulgae-a new pathogen. Tubercle 53:210214.

15. Marks, J., and T. Szulga. 1965. Thin-layer chromatography of mycobacterial lipids as an aid to classification: technical procedures. Mycobacterium fortuitum. Tubercle $46: 400-411$.

16. MeClatchy, J. K. 1981. The seroagglutination test in the study of nontuberculous mycobacteria. Rev. Infect. Dis. 3:867-870.

17. National Institutes of Health. 1980. Mycobacterial culture collection. Publication 80-289. National Institutes of Health, Bethesda, Md.

18. Schaefer, W. B. 1965. Serologic identification and classifi- cation of the atypical mycobacteria by their agglutination. Am. Rev. Respir. Dis. 92(Suppl.):85-93.

19. Schaefer, W. B. 1967. Serologic identification of the atypical mycobacteria and its value in epidemiologic studies. Am. Rev. Respir. Dis. 96:115-118.

20. Schaefer, W. B. 1967. Type-specificity of atypical mycobacteria in agglutination and antibody absorption tests. Am. Rev. Respir. Dis. 96:1165-1168.

21. Schaefer, W. B. 1980 . Serological identification of atypical mycobacteria. Methods Microbiol. 13:323-344.

22. Szulga, T., P. A. Jenkins, and J. Marks. 1966. Thin-layer chromatography of mycobacterial lipids as an aid to classification: Mycobacterium kansasii and Mycobacterium marinum. Tubercle 47:130-136.

23. Vestal, A. 1975. Procedures for the isolation and identification of mycobacteria. Publication (CDC) 77-8230. Centers for Disease Control, Atlanta, Ga.

24. Wolinsky, E. 1979. Nontuberculous mycobacteria and associated diseases. Am. Rev. Respir. Dis. 119:107-159.

25. Wolinsky, E., and W. B. Schaefer. 1973. Proposed numbering scheme for mycobacterial serotypes by agglutination. Int. J. Syst. Bacteriol. 23:182-183. 